\title{
VARIAÇÃO DA PREPOSIÇÃO "A" COMO INTRODUTORA DE ARGUMENTOS VERBAIS E DE CIRCUNSTANCIADORES LOCATIVOS NA ESCRITA JORNALÍSTICA
}

\author{
JÉSSICA MARQUES DA COSTA TOSTES ${ }^{1}$, MARLI HEMENEGILDA \\ PEREIRA $^{2}$
}

\author{
Instituto de Letras \\ Universidade Federal Fluminense \\ Rua Professor Marcos Waldemar de Freitas Reis, s/n - 24210-200 - Campus do \\ Gragoatá, Bloco B e C. São Domingos -Niterói - RJ - Brasil \\ jessicamtostes@hotmail.com \\ hpmarli@terra.com.br
}

\begin{abstract}
Resumo. Este artigo insere-se na perspectiva da sociolinguística variacionista e tem como objeto de estudo o uso variável da preposição A, em competição com as preposições EM e PARA, no esquema de transitividade verbal na escrita jornalística carioca. A amostra é composta de notícias e crônicas jornalísticas dos jornais Extra e O Globo. Considera-se que este estudo permitirá aprofundar o conhecimento sobre variação linguística no português brasileiro, uma vez que lidará com dados empíricos em situações reais de uso. A metodologia adotada para realizar esta pesquisa é de caráter qualitativo, interpretativista $e$ quantitativo, focalizando os aspectos linguísticos e sociais do fenômeno. Para a análise qualitativa, foi utilizado o arcabouço teórico $e$ metodológico da Linguística Textual e, para a análise quantitativa, foram utilizados os métodos e técnicas da sociolinguística variacionista de origem laboviana. Os resultados obtidos demonstraram que o uso variável da preposição A é ainda incipiente na escrita jornalística, modalidade, tradicionalmente, apresentada como mais conservadora em relação às escolhas linguísticas.
\end{abstract}

Palavras-chave: sociolinguística; variação linguística; uso das preposições.

\begin{abstract}
This article is part of the perspective of variation sociolinguistics and its object of study is the variable use of the preposition A, in competition with the prepositions EM and PARA, in the verbal transitivity scheme in Rio journalistic writing. The sample is composed of news and journalistic chronicles from Extra and $O$ Globo newspapers. It is
\end{abstract}

\footnotetext{
${ }^{1}$ Mestranda em Estudos de Linguagem no Instituto Letras, da Universidade Federal Fluminense IL/UFF/CAPES.

2 Professora Associada de Língua Portuguesa na graduação em Letras e na Pós- graduação (Mestrado Profissional em Letras) da Universidade Federal Rural do Rio de Janeiro.
} 
considered that this study will allow to deepen the knowledge about linguistic variation in Brazilian Portuguese, since it will deal with empirical data in real situations of use. The methodology adopted to carry out this research is of a qualitative, interpretive and quantitative character, focusing on the linguistic and social aspects of the phenomenon. For the qualitative analysis, the theoretical and methodological framework of Textual Linguistics was used and, for the quantitative analysis, the methods and techniques of the variationist sociolinguistics of Labovian origin were used. The results obtained showed that the variable use of preposition A is still incipient in journalistic writing, a modality traditionally presented as more conservative in relation to linguistic choices.

Keywords: sociolinguistics; linguistic variation; use of prepositions.

\section{INTRODUÇÃO}

A constatação de que a língua é heterogênea e variável não é recente, remonta, pelo menos, desde os estudos histórico-comparativos do século XIX. No entanto, a variação e a mudança linguísticas passaram a ser estudadas de forma sistemática e científica somente a partir da década de 60 do século XX, com os pressupostos teóricos e metodológicos da sociolinguística variacionista postulados por William Labov e colaboradores.

Os estudos acerca da variação enquanto fenômeno universal descrevem as formas linguísticas denominadas variantes. As variantes são, segundo Mollica (2003, p. 11), “... as diversas formas alternativas que configuram um fenômeno variável, tecnicamente chamado dependente." A variação das preposições A, EM e PARA no esquema de transitividade verbal é exemplo de variável dependente, pois não são concebidas aleatoriamente, mas por influência de fatores linguísticos e extralinguísticos. Tais fatores são denominados variáveis independentes. Atrelada à noção de variáveis, há a análise sociolinguística estatística/quantitativa. Essa abordagem baseia-se na utilização de modelos matemáticos com a finalidade de verificar, seja na forma falada, seja na forma escrita, a frequência de ocorrência dos fenômenos variáveis. Assim, seleciona-se um determinado corpus e, por meio do programa computacional (Goldvarb), avalia-se a porcentagem de frequência e peso relativo de determinado fenômeno.

Partindo dos pressupostos da Sociolinguística, alguns estudos apontaram o uso, na língua falada, cada vez mais restrito da preposição A como introdutora de complementos e adjuntos adverbiais, sendo substituída por PARA, em alguns contextos, ou pela preposição EM. No nordeste do Brasil, ainda é comum o uso de A, entretanto nas demais variedades o uso de PARA é quase categórico, o que explica a dificuldade que a maioria dos brasileiros apresenta em, por exemplo, grafar o "a craseado" (BAGNO, 2007). Assim, é preciso buscar estratégias de ensino que contemplem as reais necessidades da língua em uso a fim de identificar usos variáveis na fala que podem se refletir na escrita.

Considerando os pressupostos apresentados acima, este artigo apresenta o resultado de uma investigação do uso variável da preposição A, intercambiável pelas preposições PARA ou EM, no esquema de transitividade verbal na escrita jornalística 
carioca, a fim de descrever até que ponto esse fenômeno oral influencia na escrita padrão da Língua Portuguesa, pois conforme apontam Bagno (2007), Mollica e Braga (2003), no registro informal, há um uso cada vez mais restrito da preposição A nesse contexto, sendo substituída pelas preposições EM ou PARA. É importante destacar que este estudo faz parte da pesquisa desenvolvida no projeto Pibic/UFRRJ (2019/2020), financiada pelo Conselho Nacional de desenvolvimento Científico e tecnológico (CNPq).

A amostra utilizada de língua escrita é composta por crônicas (semi-informal) e notícias (mais formal), extraídas de dois jornais cariocas: Extra (mais popular) e $\mathrm{O}$ Globo (menos popular). De acordo com Bortoni-Ricardo (2004), diversos fenômenos variáveis podem estar relacionados ao contínuo de monitoração estilística, onde estão situadas desde as interações totalmente espontâneas até as totalmente planejadas, que variam num nível de menor ou maior formalidade. Acredita-se que as variáveis tipo de jornal e gênero textual podem influenciar o uso variável da preposição A.

Neste artigo, apresentam-se os resultados de uma análise sociolinguística da variação da preposição A como introdutora de argumentos verbais e circunstanciadores locativos na escrita jornalística. Na primeira seção, apresenta-se o aporte teórico da sociolinguística variacionista. Na segunda seção, faz-se uma descrição das funções da preposição A com base nas gramáticas normativas e descritivas. Na terceira seção, fazse um breve apanhado sobre o fenômeno de transitividade verbal. Na quarta seção, debruça-se sobre as particularidades dos gêneros textuais de domínio midiático. $\mathrm{Na}$ quinta seção, descreve-se a metodologia empregada na análise dos dados. Na sexta seção, analisa-se o uso da preposição A nos contextos jornalísticos selecionados.

\section{A SOCIOLINGUÍSTICA}

A Sociolinguística, postulada pelo americano William Labov e seus colaboradores na década de 1960, é uma área da linguística que estuda a língua em seu uso real, dando importância às relações entre a estrutura linguística e os aspectos sociais e culturais da linguagem. Desse modo, essa corrente defende uma visão de língua como uma instituição social, e, por isso, não pode ser estudada desconsiderando os contextos sociais, os fatores extralinguísticos, envolvidos em seu uso. Características presentes nos grupos de falantes, como escolaridade, sexo, idade, etnia, procedência, nível socioeconômico, dentre outras, são contempladas na análise. Portanto, Para a Sociolinguística a língua é heterogênea e por isso não admite a existência de uma comunidade de fala homogênea, nem um falante ideal (LABOV, 1972 [2008]).

A heterogeneidade da língua é um fator essencial para a abordagem laboviana pois, ao atribuir à língua um caráter de sistema heterogêneo, Labov se opõe diretamente aos ideais de formalistas como Saussure e Chomsky. Portanto, a variação da língua não é considerada como um caos e sim como algo sistematizado. Uma evidência disso é o fato de os indivíduos de uma comunidade se entenderem, apesar das variações linguísticas. Vale ressaltar que o princípio da heterogeneidade não implica a ausência de regras na língua e sim em uma concepção de sistema que suporte regras categóricas e, também, regras variáveis. Além de observar a variação e a mudança como inerentes às línguas, a Sociolinguística admite a presença dos componentes sociais na análise linguística e, por isso, tais questões devem ser levadas em conta nos estudos 
linguísticos. Assim sendo, um dos principais objetivos da sociolinguística é entender quais os principais fatores que motivam a variação nas línguas, através do estudo do vernáculo da língua em suas situações reais de interação nas comunidades de fala, isto é, o objetivo da pesquisa linguística na comunidade deve ser descrever como as pessoas falam quando não são sistematicamente observadas". (LABOV, 2008, p. 244)

\section{DESCRIÇÃO E USO DAS PREPOSIÇÕES A, PARA E EM NO PORTUGUÊS BRASILEIRO}

Esta seção apresenta as funções e usos das preposições investigadas neste trabalho com base em duas gramáticas de natureza normativista e duas gramáticas de natureza descritiva.

\section{ABORDAGEM NORMATIVA DAS PREPOSIÇÕES}

Na gramática de Bechara (2009), a definição apresentada pelo autor para as preposições enfatiza o papel de índice de função gramatical do termo que introduzirem na oração, desconsiderando a parte semântica dos termos.

Chama-se preposição a uma unidade linguística desprovida de independência - isto é, não aparece sozinha no discurso, salvo por hipertaxe - e, em geral, átona, que se junta a substantivos, adjetivos, verbos e advérbios para marcar as relações gramaticais que elas desempenham no discurso, quer nos grupos unitários nominais, quer nas orações. Não exerce nenhum outro tipo de papel que não seja ser índice de função gramatical do termo que ela introduz. (BECHARA, 2009, p.296)

Deste modo, o autor exemplifica em Aldenora gosta de Belo Horizonte, que a preposição "de" é responsável por unir a forma verbal "gosta" ao seu complemento "Belo Horizonte", exercendo "servidão gramatical" como a função de índice gramatical. Outro exemplo utilizado é a frase homem de coragem, em que a mesma preposição permite ao substantivo "coragem" exercer o papel de adjunto adnominal do substantivo "homem". Sendo assim, nesses casos, a preposição funciona como um elemento transpositor, permitindo que determinada unidade linguística exerça um papel gramatical distinto do que lhe é normalmente atribuído.

Cunha e Cintra (2013) destacam a significação das preposições segundo as relações estabelecidas entre as palavras. Para os autores, as preposições podem exprimir um movimento ou uma situação daí resultante. Destarte, consideram-se as referências que permitem estabelecer uma significação aplicável ao campo espacial, temporal e nocional.

O quadro comparativo a seguir apresenta as funções das preposições A, PARA e EM segundo as abordagens dos autores supracitados.

Quadro 1: Comparativo do uso da preposição A prescrito na gramática normativa.

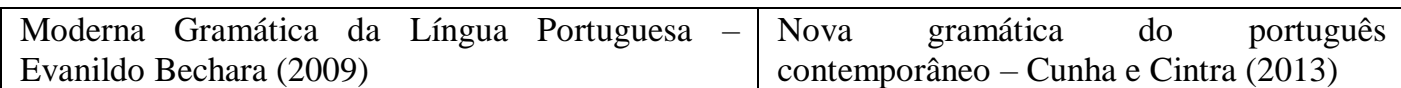




\begin{tabular}{|c|c|c|}
\hline A & $\begin{array}{l}\text { a) Introdutora de complementos verbais (objetos } \\
\text { indiretos) e nominais: (1)"Perdoamos mais } \\
\text { vezes aos nossos inimigos por fraqueza, que } \\
\text { por virtude." [MM]. (BECHARA, 2009. p. 306, } \\
\text { grifo do autor); } \\
\text { b) Introduz circunstâncias como: } \\
\text { 1. termo de movimento ou extensão: (7) "Nesse } \\
\text { mesmo dia levei-os ao Banco do Brasil" } \\
\text { [MA.1, 1511] (BECHARA, 2009. p. 307, grifo } \\
\text { do autor; } \\
\text { 2. } \\
\text { tempo em que uma coisa sucede: (8) "Indaguei } \\
\text { do guarda; disse-me que efetivamente "esse } \\
\text { sujeito" ia por ali às vezes. A que horas?" } \\
\text { [MA.1, 172] (BECHARA, 2009. p. 307, grifo } \\
\text { do autor); } \\
\text { fim ou destino: (9) Tocar à missa (= para } \\
\text { assistir à missa) (BECHARA, 2009. p. 307, } \\
\text { grifo do autor; }\end{array}$ & $\begin{array}{l}\text { a) Movimento = direção a um limite: } \\
\text { 1. no espaço: Rompo à frente, tomo a } \\
\text { mão esquerda. (C. Drummond de } \\
\text { Andrade, CB, 40.) [...] (CUNHA E } \\
\text { CINTRA, 2013. p. 577, grifos do } \\
\text { autor); } \\
\text { no tempo: Lá de ano a ano é que vinha } \\
\text { procurá-la. (M. Torga, B, 30.) } \\
\text { (CUNHA E CINTRA, 2013. p. 577, } \\
\text { grifos do autor); } \\
\text { na noção: A sua vida com o marido vai } \\
\text { de mal a pior. (J. Paço D'Arcos, CVL, } \\
\text { 937) (CUNHA E CINTRA, 2013. p. } \\
\text { 577, grifos do autor). } \\
\text { Situação = } \\
\text { concomitância: } \\
\text { 1. no espaço: Ex.: Santos cumpriu tudo à } \\
\text { risca. (Machado de Assis, OC, O, 1928) } \\
\text { (CUNHA E CINTRA, 2013. p. 577, grifos } \\
\text { do autor); } \\
\text { 2. no tempo: Ao entardecer, avistarei uma } \\
\text { povoação. (C. Castelo Branco, OS, I, 164) } \\
\text { (CUNHA E CINTRA, 2013. p. 577, grifos } \\
\text { do autor).; } \\
\text { 3.na noção: - Não podemos gastar dinheiro } \\
\text { à toa. (O. Lins, FP, 157) (CUNHA E } \\
\text { CINTRA, 2013. p. 578, grifos do autor). }\end{array}$ \\
\hline
\end{tabular}

Fonte: Adaptado de Bechara (2009, p 306 e 307) e de Cunha e Cintra (2013, p 577 e 578).

Quadro 2: Comparativo do uso da preposição PARA prescrito na gramática normativa.

\begin{tabular}{|l|l|l|}
\hline $\begin{array}{l}\text { Moderna Gramática da Língua Portuguesa } \\
- \text { Evanildo Bechara (2009) }\end{array}$ & $\begin{array}{l}\text { Nova gramática do português contemporâneo - } \\
\text { Cunha e Cintra (2013) }\end{array}$ \\
\hline
\end{tabular}




\begin{tabular}{|c|c|c|}
\hline $\begin{array}{l}\text { PAR } \\
\text { A }\end{array}$ & 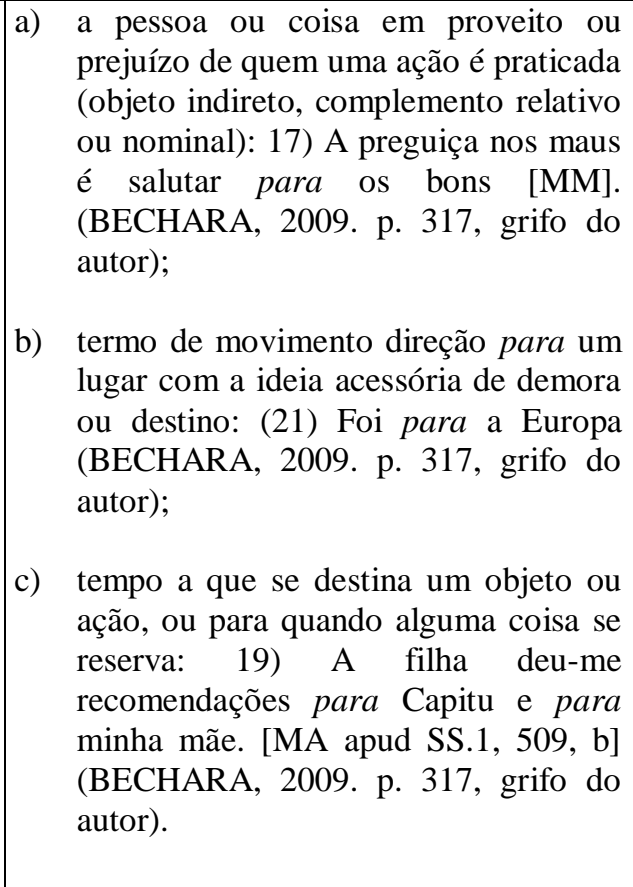 & 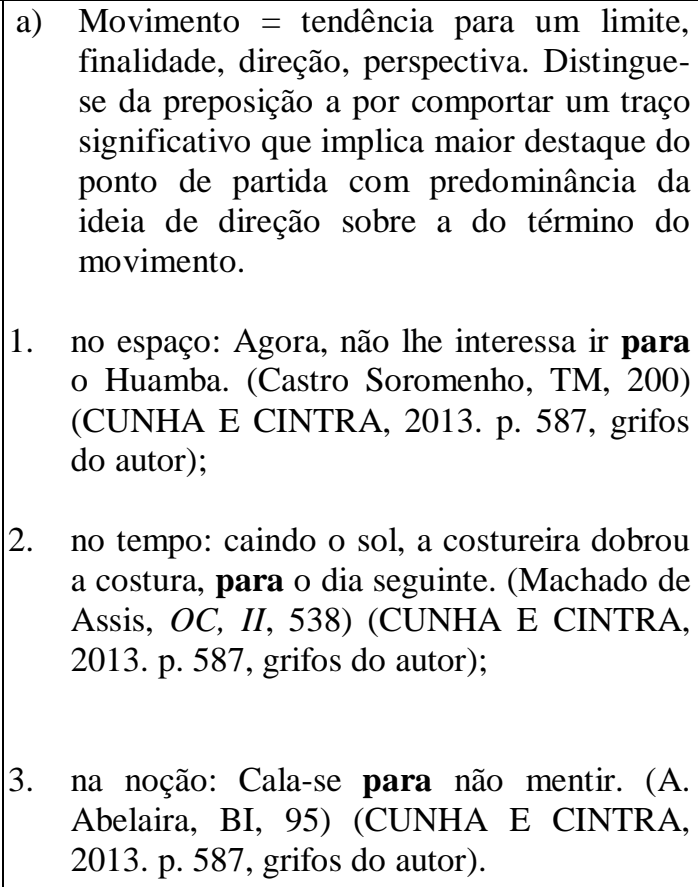 \\
\hline
\end{tabular}

Fonte: Adaptado de Bechara (2009, p 317) e de Cunha e Cintra (2013, p 587).

Quadro 3: Comparativo do uso da preposição EM prescrito na gramática normativa.

\begin{tabular}{|c|c|c|}
\hline & $\begin{array}{l}\text { Moderna Gramática da Língua Portuguesa - } \\
\text { Evanildo Bechara (2009) }\end{array}$ & $\begin{array}{l}\text { Nova gramática do português contemporâneo - } \\
\text { Cunha e Cintra (2013) }\end{array}$ \\
\hline $\begin{array}{l}\mathrm{E} \\
\mathrm{M}\end{array}$ & $\begin{array}{l}\text { a) tempo, duração, prazo: "Os homens em } \\
\text { todos os tempos, sobre o que não } \\
\text { compreenderam fabularam" [MM] [...] } \\
\text { (BECHARA, 2009. p. 315, grifo do } \\
\text { autor). } \\
\text { b) fim, destinação: Vir em auxílio. } \\
\text { (BECHARA, 2009. p. 315, grifo do } \\
\text { autor).; } \\
\text { c) lugar para onde se dirige um } \\
\text { movimento, sucessão em sentido } \\
\text { próprio ou figurado: Saltar em terra. } \\
\text { (BECHARA, 2009. p. 315, grifo do } \\
\text { autor). }\end{array}$ & $\begin{array}{l}\text { a) Movimento = superação de um limite de } \\
\text { interioridade; alcance de uma situação dentro } \\
\text { de: } \\
\text { 1. no espaço: Os Garcias entraram em casa } \\
\text { calados (V. Nemésio, MTC, 194.) } \\
\text { 2. no tempo: Nazário visitava-as de quando em } \\
\text { quando. (Coelho Netto, } O S, \text { I, 81.); } \\
\text { 3. na noção: E a lagoa entrou em festa (A, M, } \\
\text { Machado, JT, 21, grifos do autor) } \\
\text { b) Situação = posição no interior de, dentro dos } \\
\text { limites de, em contato com, em cima de: } \\
\text { no espaço: Trazia no tanque. (Agostinho } \\
\text { Neto, } S E, 106 \text {.) } \\
\text { no tempo: Tudo aconteceu em 24 horas. (C. } \\
\text { Drummond de Andrade, CB, 125, grifos do } \\
\text { autor) } \\
\text { na noção: Pareceu-lhe que toda a povoação } \\
\text { estava em chamas. (Castro Soromenho TM, } \\
\text { 255.) (Cunha e Cintra, 2013. p. } 584 \text { e 585, } \\
\text { grifos do autor) }\end{array}$ \\
\hline
\end{tabular}

Fonte: Adaptado de Bechara (2009, p 315) e de Cunha e Cintra (2013, p 584 e 585).

Após a leitura e a análise da apresentação das preposições segundo a gramática normativa, é possível ressaltar que há uma apresentação padronizada dos exemplos, a 
maioria extraída de textos literários, que não retratam os diversos usos linguísticos. Além disso, não há menção aos usos variáveis dessas preposições que, por serem mais gramaticalizadas, têm a capacidade de figurar em variados contextos sintáticos, uma vez que tiveram seus conteúdos semânticos alterados com o passar do tempo, podendo funcionar como introdutoras de adjuntos e argumentos de verbos. São justamente esses fatores que serão estudados nesta pesquisa, os usos e as variações da preposição A, intercambiável por PARA ou EM introdutoras de complementos verbais e de adjuntos adverbiais locativos na escrita jornalística. Diferente do que foi demonstrado nas gramáticas acima, o contexto jornalístico, apesar de altamente monitorado, apresenta níveis distintos de linguagem relacionados ao gênero textual e à necessidade de adequação de acordo com o perfil de seu público leitor.

\section{ABORDAGEM DAS PREPOSIÇÕES NAS GRAMÁTICAS DESCRITIVAS DO PORTUGUÊS BRASILEIRO}

Castilho (2010) apresenta uma visão funcionalista-cognitiva da linguagem. Sendo assim, estabelece um "estatuto categorial das preposições" de modo que, além de admitir que as preposições atuam como palavras invariáveis, assume que elas são reunidas em categorias de nexo, devido à aproximação com as conjunções e que produzem sentindo. Dentro dessas particularidades, as preposições são divididas entre primeira e segunda ordem: a primeira relaciona a preposição à figura e ao ponto de referência, já a segunda associa a figura ao predicado verbal e ao ponto de referência, ambas estabelecendo relações de natureza assimétrica.

Isso posto, Castilho categoriza as preposições A, EM e PARA dentro da segunda ordem - preposições de movimento no espaço no eixo horizontal - de modo a indicar o ponto final, meta. A proximidade de sentido entre essas preposições pode estar na base do seu uso intercambiável. De acordo com o auto, um aspecto comum a essas preposições é a gramaticalização ${ }^{3}$, ou seja, "podem mais facilmente ser amalgamadas a outros elementos linguísticos. (...), possuem valor semântico mais complexo (...) podem funcionar como introdutoras tanto de argumentos como de adjuntos do verbo e são mais frequentes que as menos gramaticalizadas.” (CASTILHO, 2011, p. 587).

$\mathrm{O}$ autor acrescenta ainda que a variação entre as preposições A/EM com verbos de movimento como ir, vir, levar, chegar, conduzir, mandar, voltar, mandar, descer, dentre outros, estaria associada à intenção do falante de referenciar o ponto de chegada. Desse modo, a utilização da preposição A tornaria o objeto mais geral e a preposição EM indicaria algo mais específico.

A gramática de Bagno (2011) traz uma investigação acerca dos fenômenos gramaticais do português brasileiro a partir de seus usos reais. $\mathrm{O}$ autor separa as "aposições" em quatro grupos de acordo com as seguintes distinções: 1) sintaticamente, diferencia preposições "Cheguei no Rio ontem"4 de posposições "A proposta do

\footnotetext{
${ }^{3} \mathrm{O}$ processo de gramaticalização refere-se à mudança linguística pelo qual palavras de valor lexical (substantivos, adjetivos e verbos) transformam-se em palavras ou expressões de valor gramatical (preposições, conjunções, advérbios e auxiliares).

${ }^{4}$ Neste caso, o autor admite que, no Português Brasileiro, há uma tendência de utilização da preposição EM como introdutora do circunstanciador locativo dos verbos chegar e ir, no lugar da utilização da preposição A como postula a gramática tradicional.
} 
Alfredo eu votei contra" (BAGNO, 2011. p. 854); 2) funcionalmente, diferencia entre relações predicativas concretas (causa, instrumento, acompanhamento) e relações predicativas abstratas (tempo, intenção e relações discursivas e textuais); 3) semanticamente, diferencia entre relações gramaticais abstratas (a, de, em) e as concretas (ante, após) e 4) morfologicamente, diferencia entre aposições simples (apresentam um único vocábulo), e complexas (apresentam mais de um vocábulo).

Bagno classifica as preposições considerando o processo de gramaticalização. Assim, segundo a proposta do autor, as preposições podem ser divididas em: totalmente gramaticalizadas (a, com, de, em, com, sobre, para, por) e preposições em processo de gramaticalização (até, desde, entre, sem e sob).

Ainda de acordo com Bagno (2007), os fenômenos variáveis no português brasileiro podem ser agrupados em dois conjuntos: traços graduais e traços descontínuos. Os traços linguísticos denominados graduais estão presentes na fala da maioria dos falantes, mesmo nos considerados cultos, e são característicos da variante do português brasileiro, isto é, constituem o que identifica a realidade da língua portuguesa brasileira contemporânea em uso. Esses traços possuem força social e são, aos poucos, assimilados e utilizados em gêneros textuais mais monitorados. Já os traços descontínuos são aqueles que sofrem maior carga de preconceito e discriminação, pois estão diretamente relacionados aos falantes de baixo prestígio social.

Bagno (2007) descreve uma série de traços graduais inerentes ao vernáculo brasileiro. Dentre eles, há a descrição da ocorrência do uso mais restrito da preposição A como introdutora de objetos indiretos, sendo substituída por PARA; assim como nos verbos que indicam direção ou movimento, sendo substituída por PARA ou EM. O autor destaca que a preposição A ainda é muito utilizada em algumas variantes regionais, como as nordestinas, entretanto o uso de PARA em construções com verbos transitivos indiretos é inegável. Esse fator explica a dificuldade que grande parte da população brasileira possui de, por exemplo, grafar o "a craseado". Esta pesquisa tem o intuito de investigar se esse uso variável das preposições, detectado na fala, ocorre também na escrita, mais especificamente, jornalística.

Dentre os papéis sintáticos dessas preposições listados acima, interessam, para este trabalho, seu uso como introdutora de complemento verbal e introdutora de adjunto adverbial locativo.

\section{TRANSITIVIDADE VERBAL E O USO DAS PREPOSIÇÕES}

A abordagem da transitividade verbal não é consensual nem nas gramáticas normativas nem nas gramáticas descritivas, no entanto, essa discussão não será aprofundada aqui. O objeto de interesse é o uso intercambiável das preposições A, PARA e EM como introdutoras de complementos verbais e de circunstanciadores (chamados tradicionalmente de adjuntos adverbiais) locativos. Nas gramáticas tradicionais, os complementos verbais são considerados como termos integrantes da oração, porque integram a significação transitiva do verbo e os adjuntos adverbiais são 
apresentados como termos acessórios, porque acrescentam informações circunstanciais ao verbo.

Em linhas gerais, a maioria dos gramáticos normativistas diferencia verbo intransitivo de verbo transitivo. Conceitua-se o primeiro como aqueles verbos que não exigem complemento verbal, mas podem ocorrer com adjuntos adverbiais. Verbos como nascer, morrer, crescer (indicam processo) e verbos como ir, voltar, chegar (indicam movimento) são, geralmente, citados como verbos intransitivos. Já o segundo tipo, verbos transitivos, são definidos como aqueles que precisam de complemento verbal. Se esse complemento for introduzido sem preposição, o verbo é denominado de transitivo direto; no entanto, se o complemento for encabeçado por preposição, o verbo é classificado como transitivo indireto. Há ainda o verbo bitransitivo ou transitivo direto e indireto, que exige dois complementos, um com preposição e outro sem preposição. Cunha e Cintra (2017), por exemplo, apresentam como complementos verbais o objeto direto, o objeto direto preposicionado, o objeto direto pleonástico, o objeto indireto e o objeto indireto pleonástico. Sobre esses casos, interessam para este estudo os casos de objeto indireto. Segundo os autores, o objeto indireto é "o complemento de um verbo transitivo indireto, isto é, o complemento que se liga ao verbo por meio de preposição" e pode ser representado por a) substantivo, b) pronome (substantivo), c) numeral, d) palavra ou expressão substantivada, e) oração substantiva (objetiva indireta) (CUNHA; CINTRA, 2017 p. 157 -159).

É importante sinalizar que os circunstanciadores locativos recebem status diferenciado na gramática de Rocha Lima (1997). Enquanto gramáticos como Bechara (2009) e Celso Cunha e Lindley Cintra (2017) categorizam esses elementos como adjuntos adverbiais (termos acessórios) que podem acompanhar verbos transitivos e intransitivos, o estudioso os denomina como complemento relativo (termo integrante) quando completam o sentido de verbos de movimento como, por exemplo, o verbo "ir". Para Rocha Lima, "é um complemento de natureza adverbial - tão indispensável à construção do verbo quanto, em outros casos, os demais complementos verbais" (ROCHA LIMA, 1997, p.252). Nesses casos, os verbos seriam considerados transitivos relativos.

Os conceitos expostos acima são importantes para o desenvolvimento deste trabalho porque o fenômeno estudado está diretamente relacionado à transitividade e à regência verbal. Os verbos de movimento apresentam termos introduzidos pelas preposições A, PARA e EM. Segundo a gramática tradicional, os verbos de movimento (ir, levar, chegar), devem ser empregados com a preposição A ou PARA por indicarem sentido de direção. No entanto, diversos autores como Bispo (2004) e Vieira (2009) destacam que a utilização das preposições se dá não apenas por fatores linguísticos, mas também por fatores extralinguísticos. De acordo com os autores, quanto maior a definição do verbo, maior a probabilidade de utilização da preposição EM nesses contextos. Além disso, constata-se uma forte tendência a utilizar a preposição EM quando os locativos utilizados referem-se a espaços fechados. Como no exemplo "João foi na (em + a) sorveteria no final de semana."

\section{GÊNEROS TEXTUAIS E DOMÍNIO MIDIÁTICO}


Esta pesquisa focaliza os usos variáveis das preposições nos gêneros textuais, notícia e crônica jornalística, pertencentes ao domínio discursivo jornalístico, pois a escrita jornalística é marcada por uma forte influência da variedade de prestígio, representativa da norma culta. Embora a linguagem culta seja predominante nesse âmbito, observa-se que há gêneros textuais com graus de formalidade distintos que apresentam níveis variados de linguagem. A notícia, por exemplo, é mais formal. Enquanto a crônica é menos formal. Partiu-se da hipótese de que a entrada do fenômeno variável da preposição A (intercambiável por EM ou PARA) pode ocorrer nos gêneros menos formais que tendem a favorecer a ocorrência de formas variáveis que não são aceitas pela norma culta. Como já foi mencionado, há traços linguísticos que constituem e identificam a realidade da língua portuguesa brasileira contemporânea em uso. Esses traços, diferentes dos presentes nas variedades desprestigiadas, possuem força social e são, aos poucos, assimilados e utilizados em gêneros textuais mais monitorados.

A notícia é uma composição discursiva que possui características dependentes do seu contexto gerador. Esse gênero permite ao leitor interagir por meio de reflexões nos mais diversos ambientes e tem seu potencial ampliado com dados estatísticos, fotografias, além da escolha específica e vocabulário, ordenação de informações e fontes. Trata-se de um gênero que tem relação imediata com o mundo dos fatos, entretanto não se confunde com a realidade, pois cada texto apresenta a identidade única do redator que o criou e consiste no relato de "uma série de fatos a partir do fato mais importante ou interessante, e de cada fato, a partir do espaço mais importante ou interessante" (LAGE, 1993, p.16). Desse modo, a notícia é um texto que precisa priorizar a informação correta e completa dos fatos e evitar que a subjetividade do autor interfira no texto.

A crônica caracteriza-se por uma composição discursiva constituída como uma forma de narrar fatos do cotidiano em uma intersecção entre o Jornalismo e a Literatura. (TUZINO, 2009, p. 2). Ela se enquadra em um gênero literário de assunto livre de registro sobre pequenos fatos do cotidiano como política, arte, esporte e outros diversos temas. Geralmente, o cronista faz uso de citações de personalidades e fatos históricos para compor o texto como uma forma de inovar criativamente sua fala. Além das características de construção linguística, o autor, por meio da crônica, expressa fundamentalmente sua visão de mundo, sua opinião, relatando fatos, na medida em que reflete temas, interesses, gírias, linguagem corrente e uma variedade de aspectos culturais e sociais que compõem o cotidiano em que está inserido. Por se tratar de assuntos considerados menos importantes e por ser um texto limitado espacialmente nas edições dos jornais, nas colunas ou em artigos opinativos, a crônica é tida como um gênero menor, o que, talvez, seja a característica que permita ao cronista analisar as pequenas coisas a que se propõe. (TUZINO, 2009).

A crônica, por considerar a linguagem poética, o cotidiano e sua estreita comunicação com o leitor, apresenta um estilo de linguagem mais livre e, por causa disso, é possível que o fenômeno variável em estudo ocorra nesse gênero.

\section{ASPECTOS METODOLÓGICOS}

A Sociolinguística a fim de identificar, descrever e explicar os fenômenos variáveis desenvolveu uma metodologia própria de estudo da língua. Tal abordagem permite, por 
meio dos pressupostos teóricos em que se baseia, verificar a regularidade e sistematicidade envolvida nos processos comunicativos do dia a dia. Assim, cabe ao sociolinguista detectar os contextos que favorecem a variação a partir da frequência de uso.

A abordagem variacionista considera fatores linguísticos e extralinguísticos para realizar sua análise. Inicialmente, seleciona-se uma amostra de dados reais de uso da língua (falada ou escrita) para, posteriormente, fazer o levantamento apenas das ocorrências referentes ao fenômeno variável estudado (variável dependente). Em seguida, os dados são codificados a partir de um conjunto de variáveis linguísticas e extralinguísticas (variáveis independentes). Mais adiante, esses dados são submetidos a rodadas de programas que compõem o pacote de programas (GoldVarb) que irão oferecer os dados numéricos e os pesos relativos ${ }^{5}$. Por fim, o pesquisador, à luz de pesquisas anteriores, faz a análise dos dados.

A amostra é composta de notícias (38) e crônicas jornalísticas (31), publicadas nos Jornais Extra, O Globo e JB, no período de 2001 a 2004. Foi organizada por pesquisadores do projeto PEUL (Programa de Estudos sobre o Uso da Língua) da UFRJ que iniciou suas atividades no final da década de 70 com o objetivo de descrever a sistematicidade da variação observada no português brasileiro. Para a delimitação do corpus, foram realizados a leitura e o recorte de todos os períodos sintáticos em que ocorriam verbos com a seleção da preposição A, exigida pela gramática normativa, a fim de verificar se haveria a variação da preposição A com PARA/EM.

Após a coleta dos dados, os dados foram submetidos a uma análise quantitativa a fim de observar os contextos favorecedores da substituição A pelas preposições EM/PARA.

\section{ANÁLISE DE DADOS}

Os resultados apresentados inicialmente referem-se à análise do emprego da preposição A como introdutora de objeto indireto ou circunstanciador locativo, com o designo de verificar o comportamento geral do uso dessa preposição no contexto jornalístico escrito. Conforme apontado pelas pesquisas variacionistas, essa preposição está caindo em desuso no português falado no Brasil, sendo substituída pelas preposições PARA ou EM. O intuito é observar se, na escrita jornalística, já aparecem esses usos intercambiáveis.

$\mathrm{Na}$ amostra analisada, foram encontradas 78 ocorrências, distribuídas em: 32 no gênero notícia e 46 no gênero crônica.

$\mathrm{Na}$ amostra do gênero notícia jornalística, foram encontradas 32 ocorrências verbais que exigem, de acordo com a gramática normativa, complemento ou circunstância acompanhada pela preposição A. A tabela 1 abaixo representa a classificação das ocorrências verbais.

\footnotetext{
${ }^{5}$ Os pesos relativos indicam a influência de cada grupo de fator na aplicação da regra. Quanto mais próximo de 1, maior a influência de determinado fator na realização do fenômeno.
} 
Tabela 1 - Transitividade verbal no gênero notícia

\begin{tabular}{|c|c|c|c|}
\hline Verbos & $\begin{array}{c}\text { Verbos } \\
\text { transitivos indiretos }\end{array}$ & $\begin{array}{c}\text { Verbos } \\
\text { bitransitivos }\end{array}$ & $\begin{array}{c}\text { Verbos } \\
\text { intransitivos }\end{array}$ \\
\hline 32 & 4 & 10 & 19 \\
\hline
\end{tabular}

Exemplos:

a) Verbo tradicionalmente transitivo indireto:

"Quando um jogador subir ao ataque ${ }^{6}$, por exemplo, vira para o outro e pede cobertura comentou. (Amostra notícias - JB 09-03-04 Flu em regime de concentração - Pedro Lemos, grifo nosso)".

\section{b) Verbo tradicionalmente bitransitivo:}

"PSB e PMDB podem reeditar aliança que deu à administração passada base forte na Alerj (Amostra notícias -O Globo 25-10-02 Rosinha negocia acordo para governar Alan Gripp, grifo nosso)"

\section{c)Verbo tradicionalmente intransitivo:}

"Mesmo assim, ela se mantém otimista, espelhando-se no exemplo de colegas que venceram as dificuldades e chegaram à universidade: (Amostra notícias - Extra 05-0603 Atraso põe sonho em xeque - Sem autor, grifo nosso)"

No referido gênero, não foi encontrado uso variável da preposição A. Como já foi mencionado, o gênero notícia apresenta um registro mais formal, isso pode justificar a não ocorrência de estruturas consideradas não-cultas. De um modo geral, o texto jornalístico precisa ser objetivo, simples, claro, conciso, preciso e, quanto aos verbos, é necessária atenção para não deixar sentidos incompletos. Assim, a modalidade selecionada é demarcada por uma grande atenção à utilização das regras da gramática normativa o que, de certa forma, inibe o aparecimento de variação na escrita não encontrado nas amostras (SILVA; SILVA, 2012).

$\mathrm{Na}$ amostra do gênero crônica jornalística, foram encontradas 46 ocorrências verbais que exigem, de acordo com a gramática normativa, complemento ou circunstância acompanhada pela preposição A. A tabela 2 abaixo representa a classificação das ocorrências verbais.

Tabela 2 - Transitividade verbal no gênero crônica

\begin{tabular}{|c|c|c|c|}
\hline Verbos & $\begin{array}{c}\text { Verbos transitivos } \\
\text { indiretos }\end{array}$ & Verbos bitransitivos & Verbos intransitivos \\
\hline 46 & 11 & 16 & 17 \\
\hline
\end{tabular}

Exemplos:

\section{a) Verbo tradicionalmente transitivo indireto:}

"Outro dia, perguntaram ao porta-voz do Departamento de Estado o que a Casa Branca achava de Lula ter almoçado com Chávez em seu primeiro dia no poder." (Amostra crônica - O Globo 17-01-03 Petróleo solto, arroz grudento - Luiz Garcia, grifo nosso).

\footnotetext{
${ }^{6}$ Destacamos em negrito os verbos e sublinhamos seus respectivos complementos.
} 


\section{b) Verbo tradicionalmente bitransitivo:}

É melhor que aqueles que não conseguem evitar o vício a ele dêem vazão em lugares predeterminados, sob controle do governo, fiscalização e recolhimento dos tributos correspondentes, do que compeli-los a buscar outras alternativas para continuar jogando: se ricos, despendendo seus recursos em países vizinhos (Uruguai e Paraguai) onde a atividade é lícita; se pobres, pactuando com a ilegalidade - como ocorre com o jogo de bicho. (Amostra crônica - JB 040304 - Loteria, bingo e lavagem de dinheiro - Ines Gand, grifo nosso)

\section{c)Verbo tradicionalmente intransitivo:}

"Vitória garantida, saiu às ruas em estrondosa comemoração. (Amostra crônica - JB 04 0304 - O Ipês e a ideologia do golpe - Denise de Assis, grifo nosso)".

Nos dados analisados, foi encontrada apenas uma ocorrência que não apresenta uso da preposição A previsto pela gramática normativa: "Quando chega na cidadezinha da Espanha, ela descobre como seu pecado fez mal à comunidade." (Amostra crônica O Globo 23-10-02 O Milagre do melodrama dos anos 50 - Artur, grifo nosso)

O verbo “chegar", utilizado acima, segundo a gramática normativa, é um verbo intransitivo e vem acompanhado de um circunstanciador locativo introduzido pela preposição A. No entanto, na ocorrência acima, o verbo chegar é empregado com a preposição em $+\mathrm{a}=$ na. Como já foi apresentado, esse uso é caracterizado por marcas de oralidade e apesar de, atualmente, ser amplamente utilizado na fala e na escrita informal, é considerado um desvio da norma prescrita pelas gramáticas normativas. Mesmo encontrando apenas uma ocorrência, esse dado é extremamente significativo para nossa análise, porque indica que a substituição de A por EM, amplamente atestada na fala espontânea, já está aparecendo na escrita jornalística, mesmo de forma incipiente, registro considerado culto.

Após o levantamento e análise dos 78 dados, constatou-se a ocorrência apenas de um dado variável, ou seja, a substituição de A por EM. Esses resultados demonstram que, embora esse fenômeno variável esteja presente em larga escala na língua falada, ainda não aparece de maneira relevante na escrita, pelo menos a jornalística, evidenciando o grau de monitoramento estilístico dessa modalidade. Diante disso, não se pode realizar a rodada dos dados no programa Goldvarb para aferição da frequência e peso relativo das variáveis estudadas.

\section{CONSIDERAÇÕES FINAIS}

A partir do estudo realizado, é possível tecer algumas considerações a respeito do uso variável da preposição A na escrita jornalística. Em primeiro lugar, a língua apresenta caráter variável, a exemplo do que já haviam concluído Castilho (2010 p. 590) e Bagno (2011 p. 867), de que o processo ininterrupto de mudança linguística permite que duas formas variantes convivam durante um determinado período (variação) até que 
um dos itens seja vencido ou não pela concorrência. No caso de sobrevivência de apenas uma forma linguística, haveria o processo de mudança.

A concorrência entre as preposições A, PARA e EM no português brasileiro, ainda se configura um caso de variação, já que a preposição A não foi substituída pelas outras em todos os contextos, mas apresenta um processo avançado na língua falada e aparece mesmo em contextos mais informais da modalidade escrita. Tal fenômeno ocorre em construções dativas que utilizam o objeto indireto e em construções que exprimem movimento e direção.

No entanto, a escrita jornalística, objeto deste estudo, é ainda marcada por uma forte tradição gramatical que persiste, de modo geral, na utilização prescritiva orientada pela gramática normativa, caracterizando-se por uma escrita mais polida e purista. Porém, a presença de variação na amostra analisada, embora em número reduzido, é um resultado significativo, pois demonstra a entrada incipiente desse fenômeno também na escrita, modalidade, tradicionalmente, apresentada como mais conservadora em relação às escolhas linguísticas. Considera-se, ainda, que o declínio do uso da preposição $\mathrm{A}$ em situações de oralidade torna-a mais reservada para a manifestação em situações mais monitoradas fazendo com que as construções que a empreguem sejam consideradas mais elegantes e, portanto, adequadas ao estilo jornalístico.

Destaca-se que os resultados obtidos são iniciais uma vez que a pesquisa dará prosseguimento, envolvendo mais levantamento de dados extraídos de outros gêneros midiáticos como cartas de leitor e editorial, pois os resultados obtidos demonstram a necessidade de continuar a investigação deste fenômeno em outros gêneros do domínio jornalístico e mesmo em outras amostras de escrita. Para o contexto de ensino, é importante identificar os usos variáveis dessa preposição, já que, na escrita, ela está diretamente relacionada ao fenômeno da crase, aspecto fonético sinalizado pelo acento grave. Como afirma Bagno (2011. p.874) “... ainda é preciso, no trabalho de educação linguística, ensinar os empregos da preposição a em textos mais monitorados, sem, contudo, reprimir os usos já consagrados de outras preposições." Assim, é necessário desenvolver mais pesquisas que considerem o vernáculo do português brasileiro em seus diversos contextos, não apenas para contribuir para a descrição do $\mathrm{PB}$, mas também para pesquisar as variações e mudanças que determinam a especificidade da identidade linguística plural do Brasil e que auxiliem na melhora das políticas de ensino de língua.

\section{REFERÊNCIAS}

BAGNO, Marcos. Nada na Língua é por acaso: por uma pedagogia da variação linguística. São Paulo: Parábola Editorial, 2007.

BAGNO, Marcos. Gramática Pedagógica do Português Brasileiro. São Paulo: Parábola Editorial, 2011. p. 853-879.

BECHARA, Evanildo. Moderna Gramática Portuguesa. 37 ed. Rio de Janeiro: editora nova fronteira S.A., 2009. p. 296 - 310.

BISPO, Karla Ferreira Iseke Cristina. A sintaxe do objeto indireto no português do Brasil. Dissertação (Mestrado em Linguística). Programa de pós graduação em Linguística. Brasília: UnB, 2004. 
BORTONI-RICARDO, Stella Maris. Educação em Língua Materna: a Sociolinguística em sala de aula. São Paulo: Parábola, 2004.

CASTILHO, Ataliba Teixeira. Nova Gramática do Português Brasileiro. São Paulo: Contexto, 2010. p. $584-610$.

CUNHA, Cintra; CINTRA, Lindley. Nova Gramática do Português Contemporâneo. 6 ed. Rio de Janeiro: Lexicon, 2013. p. 576-587.

FIORIN, José Luiz. Introdução à linguística. 6 ed. São Paulo: Contexto, 2011.

LAGE, Nilson. Estrutura da notícia. São Paulo: Ática, 1993. p. 10-70.

MOLLICA, Maria Cecília; BRAGA, Maria Luiza (org.). Introdução à sociolinguística: o tratamento da variação. São Paulo: Contexto, 2003. p. 9-25.

ROCHA LIMA, Carlos Henrique da. Gramática normativa da língua portuguesa. 34 ed. Rio de Janeiro: José Olympio, 1997.

SILVA, Pollyanna Honorata; SILVA Mariana Batista do Nascimento. Notícia: a fluidez de um gênero. Anais do SIELP. Volume 2, Número 1. Uberlândia: EDUFU. 2014.

TUZINO, Yolanda Maria Muniz. Crônica: uma Intersecção entre o Jornalismo e Literatura. (Monografia) Texto da Biblioteca Online de Ciências da Comunicação. Universidade Estadual de Ponta Grossa, 2009.

VIEIRA, Maria José Blaskovski. Variação das preposições em verbos de movimento. SIGNUM: Est. Ling., Londrina, v. 12, n. 1, p. 423-445, jul. 2009.

Artigo recebido em: out. de 2020.

Aprovado e revisado em: jan. de 2021.

Publicado em: fev. de 2021.

Para citar este texto:

TOSTES, Jéssica Marques da Costa; PEREIRA, Marli Hemenegilga. Variação da preposição "a" como introdutora de argumentos verbais e de circunstanciadores locativos na escrita jornalística. Entremeios [Revista de Estudos do Discurso, ISSN 2179-3514, on-line, www.entremeios.inf.br], Seção Estudos, Programa de Pós-Graduação em Ciências da Linguagem (PPGCL), Universidade do Vale do Sapucaí (UNIVÁS), Pouso Alegre (MG), vol. 23, p. 16-30, Edição especial/ 2020.

DOI: http://dx.doi.org/10.20337/ISSN2179-3514revistaENTREMEIOSvol23pagina16a30 